\title{
IN VITRO ANTIBACTERIAL ACTIVITY OF SOME ANTIHISTAMINICS BELONGING TO DIFFERENT GROUPS AGAINST MULTI-DRUG RESISTANT CLINICAL ISOLATES
}

\author{
Moustafa A. El-Nakeeb, Hamida M. Abou-Shleib, Amal M. Khalil, Hoda G. Omar, Omar M. El-Halfawy*
}

Pharmaceutical Microbiology Department, Faculty of Pharmacy, Alexandria University, Egypt.

Submitted: March 14, 2010; Approved: March 14, 2011.

\begin{abstract}
Antihistaminics are widely used for various indications during microbial infection. Hence, this paper investigates the antimicrobial activities of 10 antihistaminics belonging to both old and new generations using multiresistant Gram-positive and Gram-negative clinical isolates. The bacteriostatic activity of antihistaminics was investigated by determining their MIC both by broth and agar dilution techniques against 29 bacterial strains. Azelastine, cyproheptadine, mequitazine and promethazine were the most active among the tested drugs. Diphenhydramine and cetirizine possessed weaker activity whereas doxylamine, fexofenadine and loratadine were inactive even at the highest tested concentration $(1 \mathrm{mg} / \mathrm{ml})$. The MIC of meclozine could not be determined as it precipitated with the used culture media. The MBC values of antihistaminics were almost identical to the corresponding MIC values. The bactericidal activity of antihistaminics was also studied by the viable count technique in sterile saline solution. Evident killing effects were exerted by mequitazine, meclozine, azelastine and cyproheptadine. Moreover, the dynamics of bactericidal activity of azelastine were studied by the viable count technique in nutrient broth. This activity was found to be concentration-dependant. This effect was reduced on increasing the inoculum size while it was increased on raising the $\mathrm{pH}$. The post-antimicrobial effect of $100 \mu \mathrm{g} / \mathrm{ml}$ azelastine was also determined and reached up to $3.36 \mathrm{~h}$.
\end{abstract}

Key words: Antihistaminics; bactericidal activity; bacteriostatic activity; Gram-negative isolates; Grampositive isolates

\section{INTRODUCTION}

Antihistaminics are histamine $\mathrm{H}_{1}$-antagonists -also known as $\mathrm{H}_{1}$-receptor antagonists and $\mathrm{H}_{1}$-antihistaminics (34). Chemically, they are classified into several classes including ethanolamines, ethylenediamines, piperazines, piperidines and phenothiazines where all the classes share a certain common structural feature (33). However, pharmacologically, they are classified into first-generation, whose members are sedating, and second-generation, whose members are relatively nonsedating and more selective; such classification is now more commonly used (32).

\footnotetext{
*Corresponding Author. Mailing address: Pharmaceutical Microbiology Department, Faculty of Pharmacy, Alexandria University, El-Khartoom Square, Azarita, P.O. 21521, Alexandria, Egypt.; Tel: 002-010-8145125.; E-mail: omar.alhlfawy@alexpharmacy.edu.eg
} 
Antihistaminics are available on the market in many pharmaceutical dosage forms for a variety of uses which mainly include the management of allergic conditions and the symptomatic treatment of cough and cold when used in compound preparations (34). Other uses of some antihistaminics include their use as antiemetic, anti-motion sickness, antiparkinsonism, sleep aids and appetizers $(33,34)$.

The use of antihistaminics in the drug regimen for patients who acquire microbial infection is inevitable and that gave rise to the need to assess the antimicrobial activity of antihistaminics. Few studies were previously carried out to demonstrate the antimicrobial activity of a number of antihistaminics which belonged mainly to the first generation especially the ethanolamine and phenothiazine antihistaminics; however, the published results are rather controversial.

Dastidar et al. (20) found that diphenhydramine and bromodiphenhydramine inhibited several Gram-positive and Gram-negative strains at concentrations ranging from 0.05 to $0.2 \mathrm{mg} / \mathrm{ml}$. On the other hand, Semenitz (30) reported much higher MIC values for diphenhydramine that ranged from 1.8 to $15 \mathrm{mg} / \mathrm{ml}$. However, certain members of phenothiazine antihistaminics were shown to have MIC that ranged mostly between 10 and $200 \mu \mathrm{g} / \mathrm{ml}$ against several Gram-positive and Gram-negative bacterial strains $(16,18,21,27,29)$. Nonetheless, Shibl et al. (31) revealed MIC values as low as $1.6 \mu \mathrm{g} / \mathrm{ml}$ against a $S$. aureus strain. In addition to the varied MIC ranges, the spectrum of antibacterial activity was somehow variable in the previous studies where the tested phenothiazines were generally potent against the Gram-positive microorganisms; however their effect against the Gramnegative ones was either comparable to that against the Grampositive ones or inferior to it. Moreover, some phenothiazine antihistaminics showed certain anti-tuberculosis activity (13, 17, 36).

As previous studies were almost restricted to some of the old members of antihistaminics while the new ones particularly those belonging to the second generation of antihistaminics almost received no attention from the microbiological point of view; for that reason, this paper deals with the microbiological testing of possible activities of 10 antihistaminics belonging to both old and new generations using antibiotic multiresistant clinical isolates.

\section{MATERIALS AND METHODS}

\section{Microorganisms}

A total of twenty five bacterial isolates was used in this study belonging to two Gram-positive and four Gram-negative genera. They were human isolates identified by classical microscopical and biochemical procedures $(19,23)$. In addition, the following standard strains were used: Staphylococcus aureus (ATCC 6538P), Escherichia coli (NCTC 10418), Klebsiella pneumoniae (ATCC 35657) and Pseudomonas aeruginosa (ATCC 9027). They were maintained at $4{ }^{\circ} \mathrm{C}$ as slant cultures of sterile nutrient agar for a maximum of one month (35). Long term preservation was performed by freezing in $15 \%$ glycerol broth (26).

\section{Antihistaminics}

The antihistaminics used in this study were obtained as pure dry powders of pharmaceutical grade: Azelastine hydrochloride (Aze), Cetirizine dihydrochloride (Cet), Cyproheptadine hydrochloride (Cyp), Diphenhydramine hydrochloride (Dip), Doxylamine succinate (Dox), Fexofenadine hydrochloride (Fex), Loratadine (Lor), Meclozine hydrochloride (Mec), Mequitazine (Meq) and Promethazine (Pro). They were preserved at $4^{\circ} \mathrm{C}$.

\section{Preparation of antihistaminic stock solutions}

Specified amounts of the tested antihistaminics were accurately weighed and transferred separately into suitable sterile volumetric flasks. Water soluble antihistaminic powders (azelastine, cetirizine, cyproheptadine, diphenhydramine, doxylamine, meclozine and promethazine) were dissolved in 
sterile distilled water. Fexofenadine was dissolved in the minimal amount of methanol then diluted with sterile distilled water. Loratadine and mequitazine were dissolved in minimum amounts of $95 \%$ ethanol and dimethylsulphoxide (DMSO) respectively then diluted with sterile distilled water to form a colloidal dispersion.

\section{Determination of minimum inhibitory concentration (MIC) of antihistaminics}

The MIC of each antihistaminic against various strains employed in this study was determined by the broth macrodilution technique and the agar dilution technique as well (3).

Determination of minimum bactericidal concentration (MBC) of antihistaminics

The MBC of each antihistaminic against the tested strains was determined by the broth macrodilution technique (12) by subculturing $0.1 \mathrm{ml}$ portions of each test tube showing no visible growth in the MIC experiment into test tubes containing $5 \mathrm{ml}$ antihistaminic-free sterile nutrient broth (Oxoid).

\section{Determination of the bactericidal activity of antihistaminics using the viable count technique}

The bactericidal activity of antihistaminics in final concentrations ranging from 50 to $200 \mu \mathrm{g} / \mathrm{ml}$ was determined in sterile saline solution. Stock solutions of the antihistaminics at $10 \mathrm{X}$ the required concentrations were 10 -fold diluted into the prepared bacterial suspensions and mixed at the zero time then incubated at $37^{\circ} \mathrm{C}$ for 24 hours. The final inoculum for each of the tested isolates was $\sim 10^{6}$ cells $/ \mathrm{ml}$ in the sterile saline solution. Proper controls lacking the antihistaminics were included in each test.

Samples were aseptically withdrawn at 0,6 and $24 \mathrm{~h}$ and 10 -fold serially diluted with sterile saline solution. The number of survivors was determined by the surface viable count technique. The plates were incubated at $37^{\circ} \mathrm{C}$ for $24 \mathrm{~h}$.
Determination of the dynamics of bactericidal activity of azelastine

Dynamics of bactericidal activity of 50 and $100 \mu \mathrm{g} / \mathrm{ml}$ azelastine were determined in nutrient broth. The inoculum size used was $\sim 10^{6}$ cells $/ \mathrm{ml}$. The systems were incubated in the shaking orbital incubator (A. Gallenkamp \& Co. Ltd, United Kingdom) at $37^{\circ} \mathrm{C}$ and 35 strokes/min. Samples were aseptically withdrawn from each flask at 0, 3, 6 and 24 hours for the viable count determination.

\section{Study of the effect of some factors on the bactericidal activity of azelastine}

The effect of different factors on the bactericidal activity of azelastine was determined in nutrient broth by surface viable count technique. All systems were incubated in the shaking orbital incubator at $37^{\circ} \mathrm{C}$ and 35 strokes/min. The effect of azelastine concentrations ranging from 0 to $200 \mu \mathrm{g} / \mathrm{ml}$ was determined after withdrawing samples at 0 and 6 hours. The inoculum size used was $\sim 10^{6}$ cells $/ \mathrm{ml}$.

The effect of inoculum size was also studied; three inocula of about $10^{3}, 10^{5}$ and $10^{7}$ cells $/ \mathrm{ml}$ were used. Similarly, the effect of 4 different $\mathrm{pH}$ values $(5,6,7$ and 8 ) was studied using the corresponding sterile phosphate buffers $(14)$ at $\sim 10^{6}$ cells/ml inoculum size. The $\mathrm{pH}$ of each system was checked using $\mathrm{pH}$ meter ( $\mathrm{pH} 211$ Microprocessor $\mathrm{pH}$ meter, HANNA, Romania) after addition of azelastine and adjusted if necessary. Proper controls lacking azelastine were included for each inoculum size and $\mathrm{pH}$. After incubation, samples were aseptically withdrawn at $0,3,6$ and 24 hours for the previously described viable count technique.

Determination of the post-antimicrobial effect (PAE) of azelastine turbidimetrically (22)

An overnight broth culture of each of the selected isolates was $10^{-3}$ diluted in prewarmed sterile nutrient broth and incubated in a water-bath (GFL, Germany) at $37^{\circ} \mathrm{C}$ with agitation (50 rpm). The absorbance of the culture was monitored with a spectrophotometer using a wavelength of 600 
$\mathrm{nm}$, until an absorbance of $\sim 0.25$ was reached (equivalent to $\sim 10^{7}$ cells $/ \mathrm{ml}$ ). Treatment was carried out with $100 \mu \mathrm{g} / \mathrm{ml}$ azelastine. A control untreated flask was included in the experiment.

The bacteria-drug contact lasted $1 \mathrm{~h}$, at the end of which drug activity was stopped by performing a $10^{-3}$ dilution to the cultures in drug-free prewarmed nutrient broth. The control culture was also subjected to the same dilution and growth turbidity was determined under identical conditions without antihistaminic exposure. All the cultures were further incubated at $37^{\circ} \mathrm{C}$ with agitation and the absorbance was measured hourly at $600 \mathrm{~nm}$ until > 0.1 O.D. was reached and the PAE was calculated as described by Dominguez et al (22).

\section{RESULTS AND DISCUSSION}

In the present work, a total of 29 bacterial strains and clinical isolates obtained from different sources were used. The identified clinical isolates showed multiresistance to different extents upon testing their susceptibility to 25 different antibiotics by the disc diffusion technique (4). Multiresistance was considered on the basis that the studied clinical isolates were resistant to antibiotics belonging to at least 3 classes and up to all tested antibiotics. Whereas the standard strains used were selected so that they were sensitive to the tested antibiotics.

The bacteriostatic activity of the antihistaminics under study was investigated through MIC determination against all the tested organisms both by broth and agar dilution techniques. Both methods yielded similar results shown in Table 1. Both the standard strains and the multiresistant clinical isolates showed similar responses to the action of the antihistaminics. The Ps. aeruginosa strains were insensitive to the tested antihistaminics at the studied concentration range except the phenothiazine ones, mequitazine and promethazine. The tested phenothiazines and cyproheptadine were the most effective among the studied antihistaminics and were active against both Gram-positive and Gram-negative bacteria. The obtained MIC range of promethazine was similar to the results obtained by Kristiansen and Moratensen (27), Chakrabarty et al. (16) as well as Molnar et al.(29) concerning the MIC of promethazine. However, Shibl et al. (31) determined the MIC of promethazine against only 1 strain (S. aureus NCTC 6571 standard strain) and found it to be $6.2 \mu \mathrm{g} / \mathrm{ml}$, far lower than that obtained in the present work (Table 1). In that case, the authors only performed broth dilution technique using a different medium.

Azelastine, a new generation phthalazinone derivative, demonstrated significant bacteriostatic activity which was more pronounced against the tested Gram-positive organisms (Table 1), and hence it was used in further studies for reasons discussed later. It showed moderate activity against the tested E. coli and Klebsiella spp. strains.

Table 1. MIC ranges of antihistaminics

\begin{tabular}{|c|c|c|c|c|c|c|}
\hline \multirow{2}{*}{ Organism (number of strains) } & Meq & Pro & Сур & Aze & Others $^{1}$ & Others $^{2}$ \\
\hline & \multicolumn{6}{|c|}{$\mathrm{MIC}, \mu \mathrm{g} / \mathrm{ml}$} \\
\hline S. aureus (5) & $62.5-125$ & $125-250$ & $62.5-125$ & $125-250$ & $500-1000$ & $>1000$ \\
\hline S. epidermidis (2) & 125 & 62.5 & 125 & 125 & 1000 & $>1000$ \\
\hline E. faecium (2) & 62.5 & $62.5-125$ & 62.5 & 125 & 1000 & $>1000$ \\
\hline E. $\operatorname{coli}(6)$ & $125-250$ & $250-500$ & $125-250$ & 1000 & $500->1000$ & $>1000$ \\
\hline Klebsiella spp. (5) & $62.5-125$ & $125-250$ & $62.5-250$ & $125-1000$ & $500->1000$ & $>1000$ \\
\hline Pr. mirabilis (3) & $250-1000$ & $500-1000$ & $250-1000$ & $>1000$ & $1000->1000$ & $>1000$ \\
\hline Ps. aeruginosa (6) & 500 & $125-1000$ & $>1000$ & $>1000$ & $1000->1000$ & $>1000$ \\
\hline
\end{tabular}

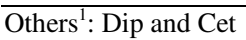

Others ${ }^{2}$ : Dox, Fex, Lor and Mec 
Other antihistaminics shown also in Table 1 possessed a slight bacteriostatic activity, under the conditions of the test, against both tested Gram-positive and Gram-negative bacteria. These histamine antagonists were diphenhydramine and cetirizine, however, they lacked activity against the Ps. aeruginosa and Pr. mirabilis isolates in the tested concentration range. This agrees in part with the findings of Semenitz (30) and Dastidar et al. (20) regarding the activity of diphenhydramine. Moreover, Semenitz (30) reported 2 to 8 folds higher MIC values than those obtained in the present study (Table 1). On the contrary, Dastidar et al. (20) mentioned $200 \mu \mathrm{g} / \mathrm{ml}$ as MIC of diphenhydramine against several $S$. aureus, E. coli, Kl. pneumoniae and Pr. mirabilis isolates. This value is approximately half to quarter the level of MIC in Table 1. The other studied antihistaminics namely meclozine, loratadine, fexofenadine and doxylamine did not exhibit any bacteriostatic effects in the studied range of concentrations (Table 1). It is noteworthy to mention that the lack of activity of meclozine might be attributed to its precipitation with the phosphates and proteins upon the addition to either nutrient agar or nutrient broth.
The bactericidal activity of the antihistaminics under study was evaluated by the dilution methods (data not shown). The MBC values of the antihistaminics were mostly identical to their MIC values. The bactericidal activity of the tested antihistaminics was also investigated by the viable count technique against 4 Gram-positive and 4 Gram-negative clinical isolates exposed for 6 and $24 \mathrm{hr}$ (Table 2). In this test, sterile saline solution which did not precipitate any of the tested antihistaminics was used. This system was also used to simulate some pharmaceutical dosage forms such as eye drops or nasal sprays or drops where the vehicle is the physiological isotonic solution. In case of azelastine, cyproheptadine and mequitazine the two concentrations used (50 and $100 \mu \mathrm{g} / \mathrm{ml}$ ) were lower than those selected for the other antihistaminics (100 and $200 \mu \mathrm{g} / \mathrm{ml}$ ) because of their relative high antibacterial activity. In general, increasing the concentration of the antihistaminics resulted in higher killing effects whenever an antihistaminic demonstrated antibacterial activity against a tested clinical isolate. However, Table 2 shows the results of the $100 \mu \mathrm{g} / \mathrm{ml}$ concentration of all tested antihistaminics to compare between their relative activities.

Table 2. Bactericidal effect of $100 \mu \mathrm{g} / \mathrm{ml}$ antihistaminics against selected isolates in $0.9 \%$ saline solution by viable count technique at $37^{\circ} \mathrm{C}$.

\begin{tabular}{|c|c|c|c|c|c|c|c|c|c|}
\hline \multirow[t]{3}{*}{ Antihistaminic } & \multirow[t]{3}{*}{ Time, h } & \multicolumn{8}{|c|}{ Organism* } \\
\hline & & $\mathbf{S a}_{103}$ & $\mathbf{S a}_{104}$ & $\mathbf{S e}_{101}$ & $\mathbf{E f}_{101}$ & $E c_{103}$ & $\mathbf{E c}_{105}$ & $\mathrm{Kl}_{102}$ & $\mathbf{P s}_{102}$ \\
\hline & & \multicolumn{8}{|c|}{ Log Plating Efficiency } \\
\hline \multirow[t]{2}{*}{ Meq } & 6 & -3.579 & -3.146 & -3.844 & -4.145 & -4.179 & -1.948 & -2.293 & -3.672 \\
\hline & 24 & -2.838 & -4.040 & -3.777 & -3.476 & -3.426 & -2.558 & -3.845 & -2.796 \\
\hline \multirow{2}{*}{ Сур } & 6 & -1.389 & -1.032 & -0.013 & -1.192 & -0.062 & -0.320 & 0.029 & -0.393 \\
\hline & 24 & -1.663 & -2.087 & -0.456 & -2.176 & 0.068 & -1.102 & 0.014 & -0.199 \\
\hline \multirow[t]{2}{*}{ Aze } & 6 & -2.580 & -1.690 & -0.289 & -3.146 & -3.702 & -0.550 & -0.110 & -0.371 \\
\hline & 24 & -2.838 & -2.699 & -1.875 & -3.476 & -5.264 & -1.373 & -0.474 & -0.489 \\
\hline \multirow[t]{2}{*}{ Mec } & 6 & 0.363 & -1.243 & -1.146 & -1.192 & -0.599 & -1.333 & -0.069 & -1.092 \\
\hline & 24 & -2.838 & -4.040 & -2.477 & -2.000 & 0.078 & -2.868 & -0.469 & -0.799 \\
\hline \multirow[t]{2}{*}{ Dip } & 6 & -0.103 & -0.544 & 0.196 & -0.146 & -0.096 & -0.032 & 0.083 & -0.009 \\
\hline & 24 & -1.839 & -0.087 & -0.234 & -1.097 & 0.014 & -1.248 & -0.026 & -0.246 \\
\hline \multirow[t]{2}{*}{ Cet } & 6 & -0.349 & -0.669 & -0.088 & -0.867 & -0.660 & -0.897 & -0.008 & -0.029 \\
\hline & 24 & -1.838 & -3.040 & -0.499 & -1.097 & -1.094 & -1.558 & -0.117 & -0.938 \\
\hline \multirow[t]{2}{*}{ Dox } & 6 & 0.101 & 0.385 & -0.414 & 0.000 & 0.131 & 0.249 & 0.071 & -0.417 \\
\hline & 24 & 0.349 & 0.357 & -1.632 & -0.310 & 0.043 & -0.409 & 0.012 & -0.074 \\
\hline \multirow[t]{2}{*}{ Fex } & 6 & 0.312 & 0.535 & 0.234 & -0.105 & 0.062 & 0.103 & -0.026 & -0.827 \\
\hline & 24 & 0.426 & -0.219 & -0.135 & -0.316 & 0.057 & -1.134 & 0.024 & -1.090 \\
\hline \multirow[t]{2}{*}{ Lor } & 6 & -0.376 & -0.209 & 0.058 & -0.327 & 0.165 & 0.282 & -0.008 & -0.330 \\
\hline & 24 & -0.392 & -1.082 & -0.444 & -0.394 & -0.032 & -0.524 & -0.017 & -0.881 \\
\hline
\end{tabular}

*Organisms. $\mathrm{Sa}_{103}$ and $\mathrm{Sa}_{104}:$ S. aureus isolates, $\mathrm{Se}_{101}:$ S. epidermidis, $\mathrm{Ef}_{101}:$ E. faecium isolate, $\mathrm{Ec}_{103}$ and $\mathrm{Ec}_{105}:$ E. coli isolates,

$\mathrm{Kl}_{102}$ : Kl. Pneumonia isolate, $\mathrm{Ps}_{102}$ : Ps. aeruginosa isolate 
Again, mequitazine demonstrated significant bactericidal effects against all the tested clinical isolates including Ps. aeruginosa (Table 2). However, its effect against the Grampositive isolates was more pronounced. Azelastine and cyproheptadine also exhibited remarkable killing activities mainly against the Gram-positive isolates (Table 2). Cetirizine and diphenhydramine also produced moderate bactericidal effects, but in relatively higher concentration (data not shown).

In the above mentioned bactericidal activity tested in saline solution, meclozine showed remarkable bactericidal effects against all the tested clinical isolates being more active against the Gram-positive ones (Table 2). This was contrary to the results of the MIC experiment in which precipitation of the drug occurred with the test medium. From the above bactericidal activity of antihistaminics estimated in saline solution, it can be concluded that active growth of the tested organisms does not seem to be essential for whatever antibacterial activity that the drugs might have.

The variation in the magnitude of antibacterial effects among different antihistaminics is however difficult to explain since screening the literature revealed that no extensive studies were published on the antibacterial activity of the different classes of antihistaminics. Thus, reviewing a possible explanation of such varied antimicrobial activity will be attempted. Such explanation may relate the mechanism of antibacterial action of antihistaminics to their chemical structure by analogy with other therapeutic classes having similar structural features. Since the main structural feature of antihistaminics is a tertiary amino group and a bulky lipophilic aromatic moiety, they possess certain surfactant-like characters $(5,11)$. Owing to surface activity of amphipathic compounds, it has been reported that they might cause alteration in the function and permeability of biological membranes in general $(25,28)$. The extent of adsorption onto the membranes due to surface activity has been correlated with their damaging effects $(1,10)$. These postulates were investigated by Shibl et al. (31) who demonstrated that certain phenothiazine antihistaminics could be adsorbed onto the surface of the bacterial cells which might facilitate their effect on their membranes. It has been stated that increasing the hydrophobicity increases the surface activity (6). Therefore, based on this assumption, antihistaminics with the most powerful antibacterial activity should be the most surface-active and be highly hydrophobic. The phenothiazine derivatives for example, possess considerable surface activity where their CMC is relatively low and aggregation number is high owing to their hydrophobic characters gained partly by the sulphur atom in the phenothiazine ring (2). Thus, both promethazine and mequitazine exhibit recognizable antibacterial effects. Similarly, cyproheptadine, having considerable surface activity (10), manifests marked antibacterial effects. Likewise, the chlorine atom substituent in the aromatic rings of meclozine and azelastine $(15,24)$ increases their surface activity and reduces their CMC values (10). On the other hand, moderate antibacterial activity seems to be related to intermediate surface characters. Diphenhydramine, having moderate surface activity manifested as intermediate CMC values (5), demonstrated certain antibacterial effects. Similarly, cetirizine have reduced surface properties, although possessing a chlorine substituent which should increase its hydrophobic character, as the sustituent's effect is counteracted by the highly hydrophilic carboxylic group substituent. The rest of antihistaminics demonstrated poor antimicrobial activity which matched with their low surface characters where both loratadine and fexofenadine show considerable hydrophilic characters imparted by ester group attached to the nitrogen atom in the former and a hydroxyl group substituent in the latter which would significantly reduce their surface activity and consequently the possible effect upon the membranes (10). On the other hand, doxylamine although belonging to the same chemical class as diphenhydramine, it possessed much weaker antibacterial effect. This might be attributed to the different counter ion effect (succinate) which may lead to altered surface activity and change in the aggregation character from micelle 
formation to a stacking process: continuous self-association with no CMC $(6,8)$.

After screening antihistaminics, representing most of the chemical classes of the histamine $\mathrm{H}_{1}$-antagonists and belonging to both first and second generations, for bacteriostatic and bactericidal activities, further studies were performed on azelastine in order to investigate its observed antibacterial activity. This antihistaminic is relatively new, belonging to the phthalazinone class of antihistaminics and showed promising antimicrobial activity. Moreover, it is clinically used locally as nasal sprays and eye drops and its therapeutic dose lies within the range of its demonstrated antibacterial activity. And since no studies regarding the microbiological aspect of this antihistaminic or any member of its class were available, it has been of interest to investigate its antimicrobial activity.

The dynamics of bactericidal activity of azelastine was also determined by the viable count technique. Since it possessed marked killing effects, 2 concentrations of azelastine were tested against 3 Gram-positive and 2 Gram-negative clinical isolates. Azelastine continued to demonstrate powerful bactericidal effects against the tested clinical isolates especially against the Gram-positive ones (Fig. 1) whereas the higher tested concentration was required to exert similar effects against the tested E. coli isolate (not shown). However, it lacked the activity against Ps. aeruginosa isolate as shown also in the previous experiments.
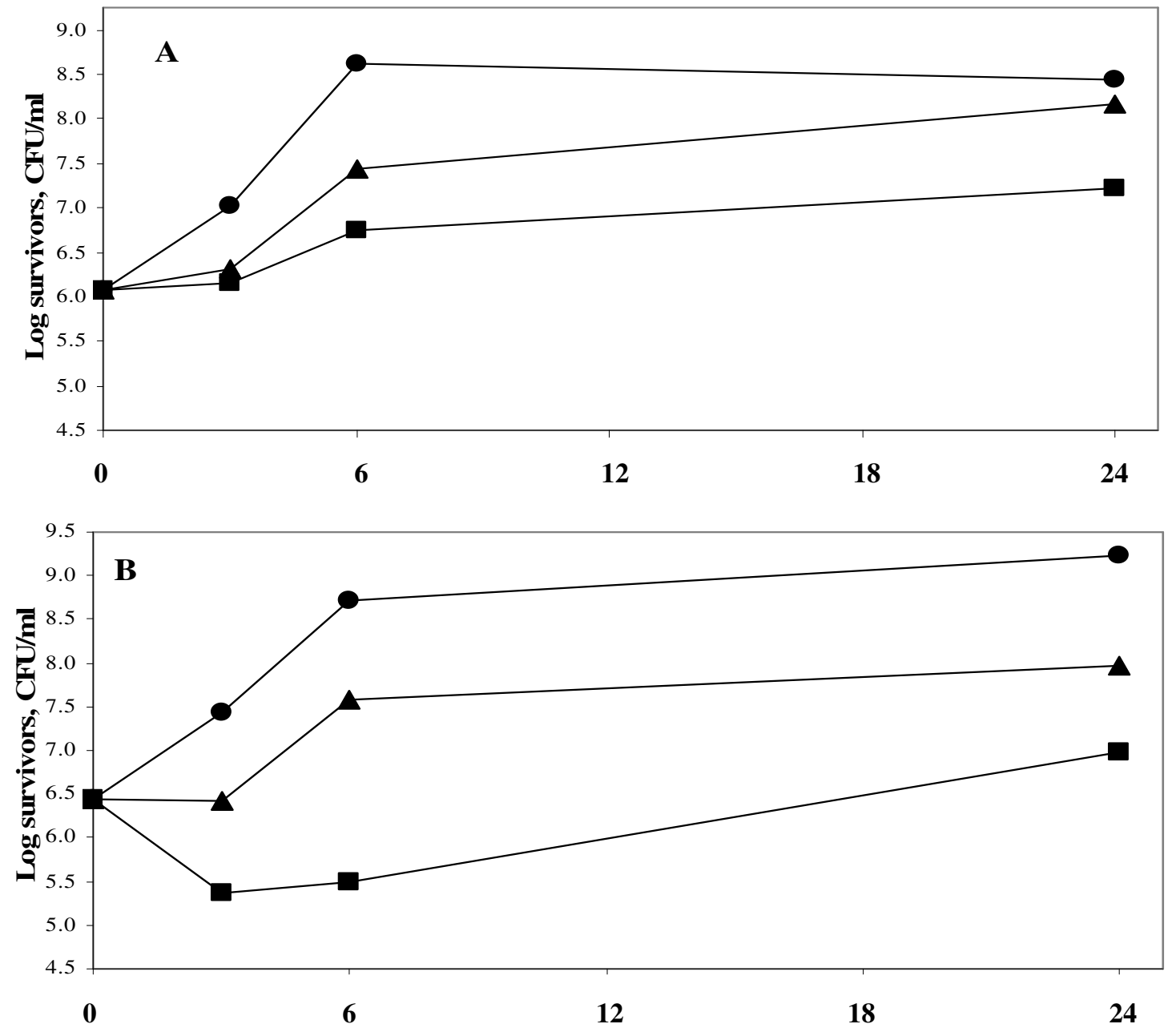


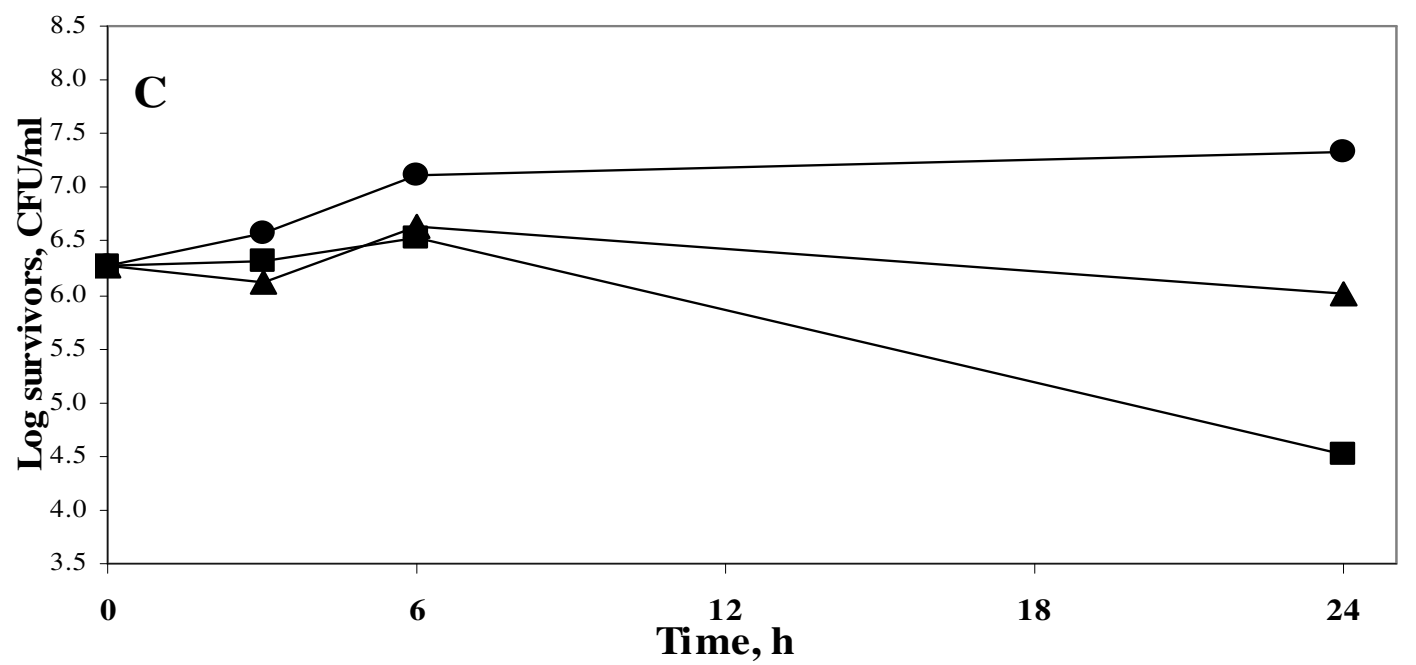

Figure 1. Dynamics of the antibacterial activity of Aze 50 and $100 \mu \mathrm{g} / \mathrm{ml}$ against

S. aureus $\mathrm{Sa}_{103}(\mathrm{~A})$, S. aureus $\mathrm{Sa}_{104}(\mathrm{~B})$ and E. faecium $\mathrm{Ef}_{101}(\mathrm{C})$ isolates at $37^{\circ} \mathrm{C}$

- Control; $\Delta$ Aze50; - Aze100

The effect of some factors was studied on the bactericidal activity of azelastine. First, the activity of azelastine was tested in different concentrations ranging between 0 and $200 \mu \mathrm{g} / \mathrm{ml}$. The outcome of this experiment showed that the antihistaminic bactericidal activity was in general concentration-dependant (Fig. 2). Table 3 showed that the bactericidal activity of azelastine increased by decreasing the inoculum sizes of the tested organisms in most cases. The inoculum size effect seems to be dependant on the ratio between antihistaminic molecules and the number of cells. In case of low inoculum, the drug could saturate more of the available sites of adsorption and hence be more active. The effect of $\mathrm{pH}$ of the medium on the bactericidal activity of azelastine is shown in Fig. 3. Fig. 3A reveals that raising the $\mathrm{pH}$ of the medium steadily increased the bactericidal effect of azelastine against the $S$. aureus isolate under study. On the other hand, azelastine almost had no effect against E. coli $\mathrm{Ec}_{103}$ isolate at slightly acidic or neutral $\mathrm{pH}$. However, the bactericidal activity dramatically increased at $\mathrm{pH} 8$ both at 3 and $6 \mathrm{hr}$ (Fig. 3B). The $\mathrm{pH}$ of the medium affects the surface activity and aggregation properties of the antihistaminics $(9,37)$. At low $\mathrm{pH}$ values, protonation of tertiary amine groups occurs leading to elevated critical micelle concentrations (CMC) as well as lower aggregation number (n, the number of monomer molecules forming the micelle). At $\mathrm{pH}$ values approaching the pKa, an increase in the aggregation number occurs due to the increased percentage of the non-ionized more hydrophobic base. Thus, it has been reported that the nonprotonated drug present at high $\mathrm{pH}$ values demonstrated a dramatic increase in the surface activity (37). It was also reported that as the hydrophobicity of compounds increased, their effect on membranes increased $(10,25)$. This might be the reason beyond the increased antibacterial effects of azelastine against the tested isolates at high $\mathrm{pH}$ values especially at $\mathrm{pH} 8$ (Fig. 3). This also agreed with Attwood and Udeala (7) who reported that the surface pressure increase was larger in the presence of phosphate buffer at $\mathrm{pH}$ 6-8, nonetheless, they were not sure whether this effect was caused by the buffer components or was a $\mathrm{pH}$ effect.

Finally, the post-antimicrobial effect of azelastine was studied against one S. aureus and another E. coli isolates (Fig. 4). The post-exposure effect was sustained for $3.36 \mathrm{hr}$ against the tested $S$. aureus isolate compared to only about half an hour for the $E$. coli isolate. This effect might be beneficial in reducing the dose and prolonging the time interval of administration thus decreasing any possible adverse effects. 


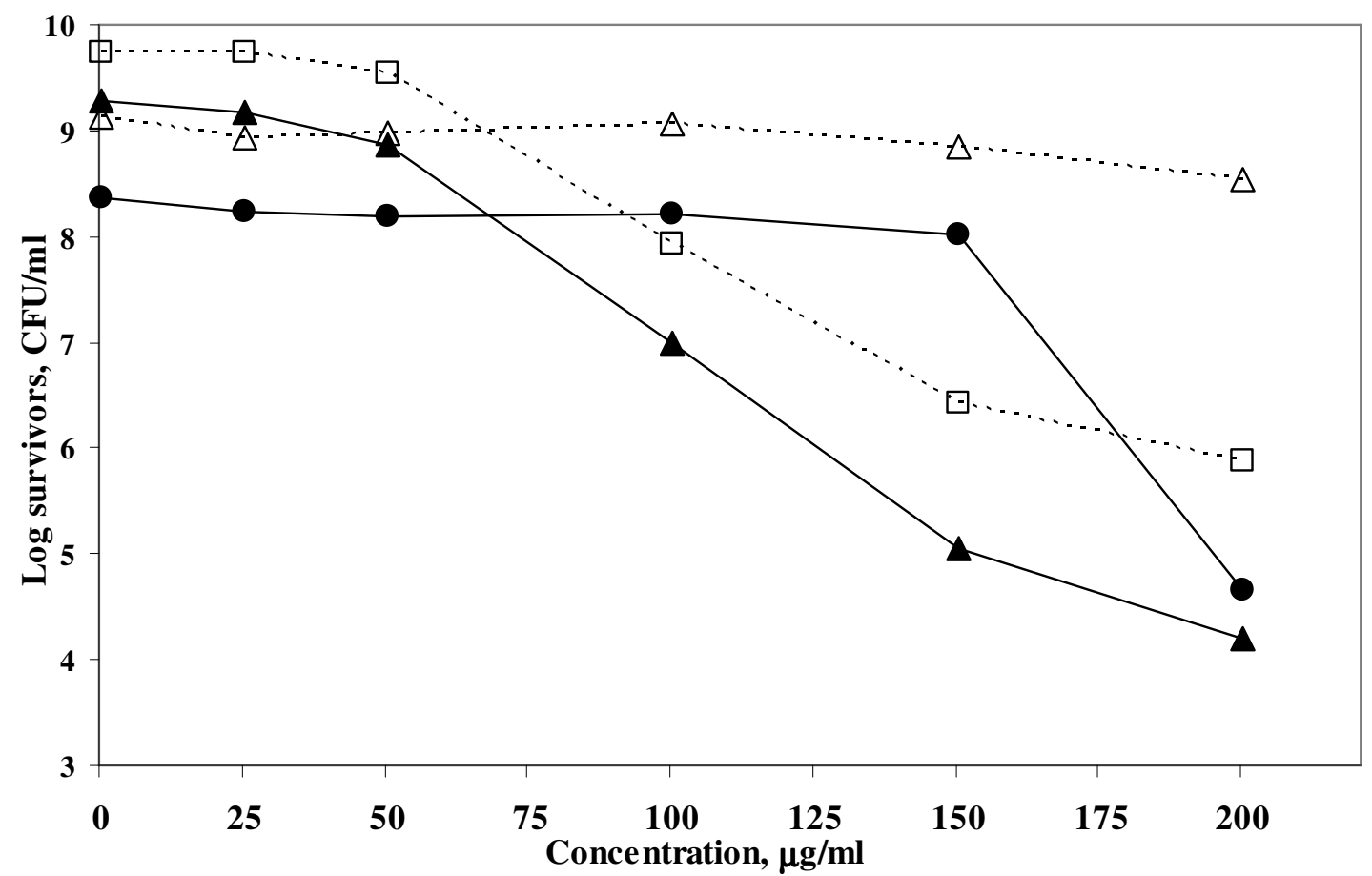

Figure 2. Effect of Aze concentrations on the growth of 5 clinical isolates at 6 hours using the viable count technique. The following initial inocula ( $\log \mathrm{CFU} / \mathrm{ml})$ were used in nutrient broth at $37^{\circ} \mathrm{C}$ :

$\Delta \mathrm{Sa}_{104}: 6.53 ; \bullet \mathrm{Ef}_{101}: 6.71 ; \square \mathrm{Ec}_{103}: 6.97$ and $\Delta \mathrm{Ps}_{102}: 6.52$

Table 3. Effect of inoculum size on the dynamics of antibacterial activity of Aze $50 \& 100 \mu \mathrm{g} / \mathrm{ml}$ against $S$. aureus Sa 103 and $E$. coli $\mathrm{Ec}_{103}$ isolates by viable count technique at $37^{\circ} \mathrm{C}$

\begin{tabular}{|c|c|c|c|c|c|}
\hline \multirow{3}{*}{ Organism } & \multirow{3}{*}{$\begin{array}{c}\text { Aze Conc. } \\
\mu \mathrm{g} / \mathrm{ml}\end{array}$} & \multirow{3}{*}{ Time, h } & \multicolumn{3}{|c|}{ Inoculum Size (cells/ml) } \\
\hline & & & $\sim 10^{3}$ & $\sim 10^{5}$ & $\sim 10^{7}$ \\
\hline & & & \multicolumn{3}{|c|}{ Log Plating Efficiency } \\
\hline \multirow{6}{*}{$\mathrm{Sa}_{103}$} & \multirow{3}{*}{50} & 3 & -0.125 & -0.501 & -0.495 \\
\hline & & 6 & -0.500 & -1.710 & -0.806 \\
\hline & & 24 & -2.624 & -0.885 & -0.986 \\
\hline & \multirow{3}{*}{100} & 3 & -1.246 & -0.692 & -0.732 \\
\hline & & 6 & -1.830 & -1.820 & -1.533 \\
\hline & & 24 & -3.584 & -1.381 & -1.361 \\
\hline \multirow{6}{*}{$\mathrm{Ec}_{103}$} & \multirow{3}{*}{50} & 3 & -0.371 & -0.068 & -0.051 \\
\hline & & 6 & -0.911 & -0.051 & 0.067 \\
\hline & & 24 & -0.100 & -0.033 & -0.060 \\
\hline & \multirow{3}{*}{100} & 3 & -0.688 & -0.402 & -0.153 \\
\hline & & 6 & -1.251 & -1.302 & -0.514 \\
\hline & & 24 & -0.913 & -0.492 & -0.557 \\
\hline
\end{tabular}



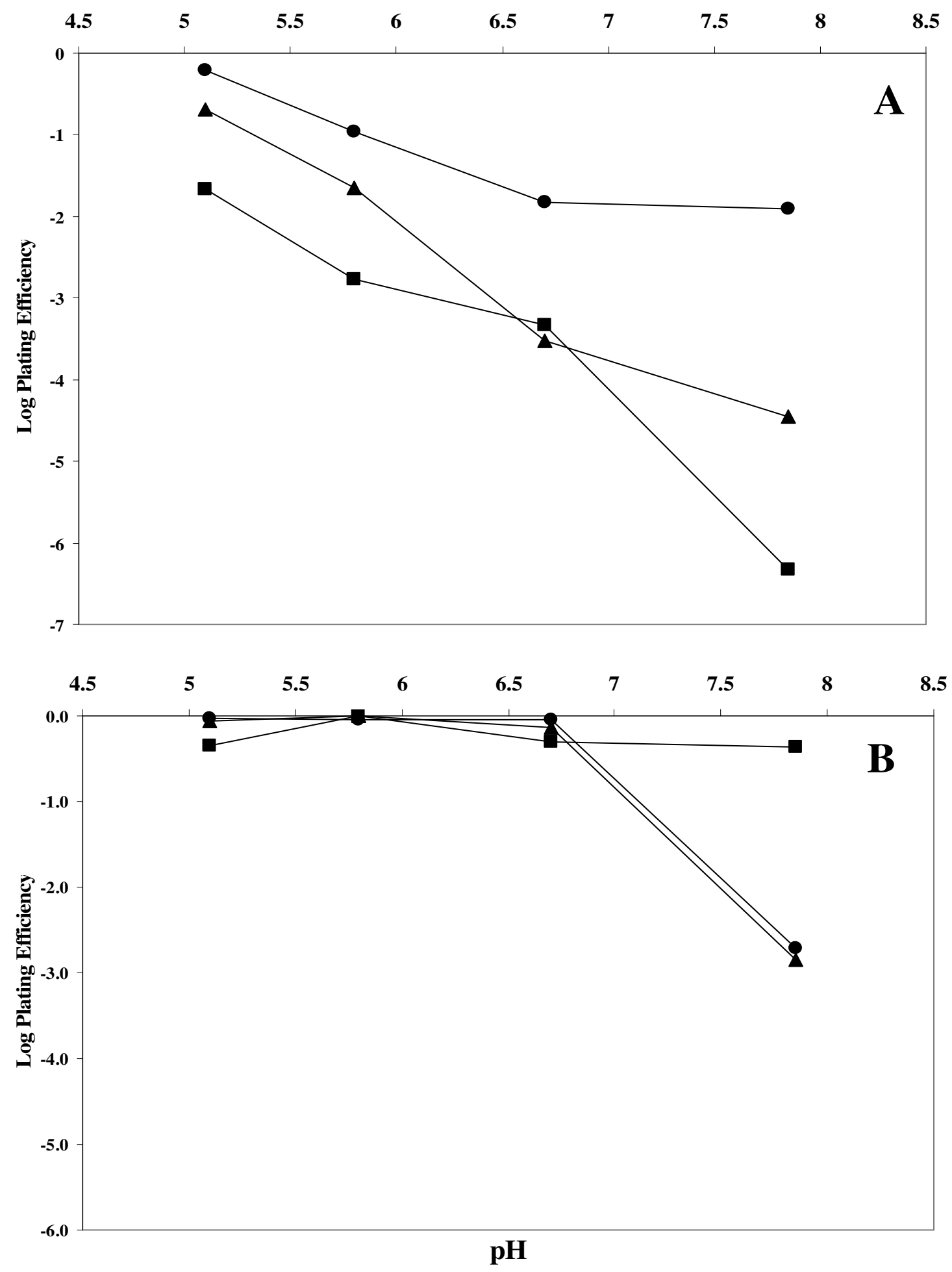

Figure 3. Effect of $\mathrm{pH}$ on the antibacterial activity of Aze $100 \mu \mathrm{g} / \mathrm{ml}$ against $S$. aureus $\mathrm{Sa}_{103}$ (A) and E. coli $\mathrm{Ec}_{103}$ (B) isolates by viable count technique at $37^{\circ} \mathrm{C}$

- $3 \mathrm{~h} ; \boldsymbol{\Delta} 6 \mathrm{~h} ; \boldsymbol{\nabla} 24 \mathrm{~h}$ 


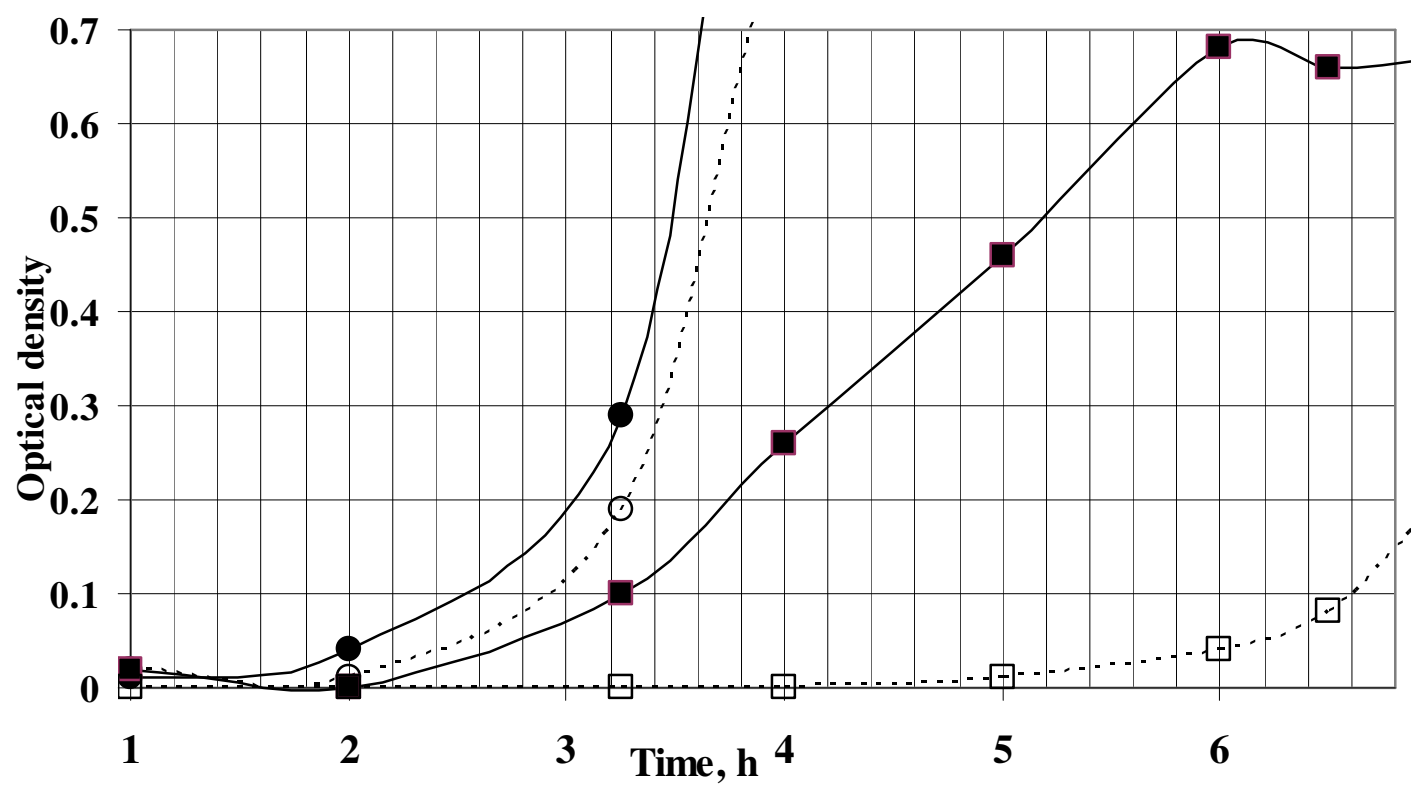

Figure 4. Turbidimetric growth curves showing PAE of Aze against S. aureus $\mathrm{Sa}_{103}$ and E. coli $\mathrm{Ec}_{103}$ clinical isolates

- $\mathrm{Sa}_{103}$ control; $\square \mathrm{Sa}_{103}$ treated with Aze; $\bullet \mathrm{Ec}_{103}$ control; $\circ \mathrm{Ec}_{103}$ treated with Aze

\section{REFERENCES}

1. Abernathy, C.O.; Lukacs, L.; Zimmerman, H.J. (1975). Toxicity of tricyclic antidepressants to isolated rat hepatocytes. Biochem Pharmacol 24(3), 347-50.

2. Ahmed, M.; Hadgraft, J.; Burton, J.S.; Kellaway, I.W. (1980). The interaction of mequitazine with phospholipid model membranes. Chem Phys Lipids 27(3), 251-62.

3. Andrews, J.M. (2001). Determination of minimum inhibitory concentrations. J Antimicrob Chemother 48 Suppl 1, 5-16.

4. Andrews, J.M. (2007). BSAC standardized disc susceptibility testing method (version 6). J Antimicrob Chemother 60(1), 20-41.

5. Attwood, D.; Udeala, O.K. (1974). Aggregation of antihistamines in aqueous solution: micellar properties of some diphenylmethane derivatives. J Pharm Pharmacol 26(11), 854-60.

6. Attwood, D.; Udeala, O.K. (1975). The surface activity of some antihistamines at the air-solution interface. J Pharm Pharmacol 27(10), 754-58.

7. Attwood, D.; Udeala, O.K. (1975). The interaction of antihistamines with lecithin monolayers. J Pharm Pharmacol 27(11), 806-10.

8. Attwood, D.; Udeala, O.K. (1976). Aggregation of antihistamines in aqueous solution: effect of counterions on self-association of pyridine derivatives. J Pharm Sci 65(7), 1053-7.

9. Attwood, D.; Natarajan, R. (1981). Effect of $\mathrm{pH}$ on the micellar properties of amphiphilic drugs in aqueous solution. J Pharm Pharmacol 33(3), 136-40.
10. Attwood, D.; Florence, A.T. (1983). Surfactant systems: Their chemistry, pharmacy and biology. Chapman and Hall Ltd., London, p. 124-228, 388-468, 607-610.

11. Attwood, D.; Florence, A.T. (1998). Physicochemical principles of pharmacy. Macmillan, London, p. 199-250.

12. Barry, A.L.; Craig, W.A.; Nadler, H.; Reller, L.B.; Sanders, C.C.; Swenson, J.M. (1999). Methods for Determining Bactericidal Activity of Antimicrobial Agents; Approved Guideline. NCCLS document M26-A, Vol. 19 (18). NCCLS, Pennsylvania, USA.

13. Bettencourt, M.V.; Bosne-David, S.; Amaral, L. (2000). Comparative in vitro activity of phenothiazines against multidrug-resistant Mycobacterium tuberculosis. Int J Antimicrob Agents 16(1), 69-71.

14. British-Pharmacopoeia-Commission, ed. (2007). Appendix I D. British Pharmacopoeia. The British Stationery Office on behalf of the Medicines and Healthcare products Regulatory Agency (MHRA), London, United Kingdom.

15. Brockman, H.L.; Momsen, M.M.; Knudtson, J.R.; Miller, S.T.; Graff, G.; Yanni, J.M. (2003). Interactions of olopatadine and selected antihistamines with model and natural membranes. Ocul Immunol Inflamm 11(4), 247-68.

16. Chakrabarty, A.N.; Acharya, D.P.; Neogi, D.; Dastidar, S.G. (1989). Drug interaction of promethazine \& other non-conventional antimicrobial chemotherapeutic agents. Indian J Med Res 89, 233-7.

17. Chakrabarty, A.N.; Bhattacharya, C.P.; Dastidar, S.G. (1993). Antimycobacterial activity of methdilazine (Md), an antimicrobic phenothiazine. Apmis 101(6), 449-54. 
18. Chattopadhyay, D.; Dastidar, S.G.; Chakrabarty, A.N. (1988). Antimicrobial properties of methdilazine and its synergism with antibiotics and some chemotherapeutic agents. Arzneimittelforschung 38(7), 869-72.

19. Collee, J.G.; Miles, R.S. (1989). Tests for identification of bacteria. In: Collee, J.G.; Duguid, J.P.; Fraser, A.G., and Marmion, B.P. (eds). Mackie and McCartney, Practical medical microbiology. Churchill Livingstone, New York, p. 141-160.

20. Dastidar, S.G.; Saha, P.K.; Sanyamat, B.; Chakrabarty, A.N. (1976). Antibacterial activity of ambodryl and benadryl. J Appl Bacteriol 41(2), 209-14.

21. Dastidar, S.G.; Jairaj, J.; Mookerjee, M.; Chakrabarty, A.N. (1997) Studies on antimicrobial effect of the antihistaminic phenothiazine trimeprazine tartrate. Acta Microbiol Immunol Hung 44(3), 241-7.

22. Dominguez, M.C.; de La Rosa, M.; Borobio, M.V. (2001). Application of a spectrophotometric method for the determination of post-antibiotic effect and comparison with viable counts in agar. J Antimicrob Chemother 47(4), 391-8.

23. Finegold, S.M.; Baron, E.J., eds (1986). Bailey and Scott's Diagnostic Microbiology. The C. V. Mosby company, St. Louis, p. 70-125, 173-201, 355-387, 397-437, 859-914.

24. Graff, G.; Miller, S.T.; Yanni, J.M.; Momsen, M.M.; Brockman, H.L. (2004). The effects of olopatadine, desloratadine, ketotifen, azelastine, and epinastine on membrane stability. Journal of Allergy and Clinical Immunology 113(2, Supplement 1), S328.

25. Guth, P.S.; Spirtes, M.A. (1964). The Phenothiazine tranquilizers: Biochemical and Biophysical Actions. Int Rev Neurobiol 7, 231-78.

26. Howard, D.H. (1956). The preservation of bacteria by freezing in glycerol broth. J Bacteriol 71(5), 625.

27. Kristiansen, J.E.; Mortensen, I. (1987). Antibacterial effect of four phenothiazines. Pharmacol Toxicol 60(2), 100-3.

28. Molnar, J.; Kiraly, J.; Mandi, Y. (1975). The antibacterial action and Rfactor-inhibiting activity by chlorpromazine. Experientia 31(4), 444-5.

29. Molnar, J.; Mandi, Y.; Kiraly, J. (1976). Antibacterial effect of some phenothiazine compounds and R-factor elimination by chlorpromazine. Acta Microbiol Acad Sci Hung 23(1), 45-54.

30. Semenitz, E. (1978). [The antibacterial activity of diphenhydramine (author's transl)]. Wien Klin Wochenschr 90(19), 710-4.

31. Shibl, A.M.; Hammouda, Y.; Al-Sowaygh, I. (1984). Comparative effects of selected phenothiazine tranquilizers and antihistaminics on bacterial cells and possible interactions with antibiotics. J Pharm Sci 73(6), 841-3.

32. Simons, F.E. (2004). Advances in $\mathrm{H}_{1}$-antihistamines. $N$ Engl $J$ Med 351(21), 2203-17.

33. Skidgel, R.A.; Erdǒs, E.G. (2006). Histamine, bradykinin, and their antagonists. In: Brunton, L.; Lazo, J., and Parker, K. (eds). Goodman and Gilman's the pharmacological bases of therapeutics. McGraw-Hill medical publishing division, New York, p. 629-652.

34. Sweetman, S.C., ed. (2002). Martindale, the complete drug reference. 33rd ed. Pharmaceutical press, London, p. 110-270, 404-427, 1201-1254.

35. Vandepitt, J.; Engbaek, K.; Piot, P.; Heuck, C.C. (1991). Basic Laboratory Procedures in Clinical Bacteriology. World Health Organization, Geneva, p. 13-15.

36. Viveiros, M.; Amaral, L. (2001). Enhancement of antibiotic activity against poly-drug resistant Mycobacterium tuberculosis by phenothiazines. Int J Antimicrob Agents 17(3), 225-8.

37. Zografi, G.; Munshi, M.V. (1970). Effect of chemical modification on the surface activity of some phenothiazine derivatives. J Pharm Sci 59(6), 819-22. 